\title{
Common Symptoms and Distress Experienced Among Patients with Colorectal Cancer: A Qualitative part of Mixed Method Design
}

\author{
Sussanne Börjeson ${ }^{1,2}$, Hans Starkhammar ${ }^{1}$, Mitra Unosson ${ }^{3}$ and Carina Berterö ${ }^{*}, 1$ \\ ${ }^{I}$ Department of Medical and Health Sciences, Linköping University, Sweden \\ ${ }^{2}$ Oncological Clinic, County Council of Östergötland, Linköping Sweden \\ ${ }^{3}$ Department of Social and Welfares Studies, Linköping University, Campus Norrköping, Sweden
}

\begin{abstract}
Background: Colorectal cancer is one of the most common types of tumour in the world. Treatment side effects, together with the tumour symptoms, can result in a 'symptom burden'. To understand the patient's burden during chemotherapy treatment and plan effective symptom relief there is a need for more knowledge about the experience of symptoms from the patients' perspective.

Objectives: The study was designed to qualitatively identify and describe the most common symptoms among patients treated for colorectal cancer, and discover whether there are barriers to reporting symptoms. Methods: Thirteen Swedish patients diagnosed with colorectal cancer and treated with chemotherapy were interviewed face-to-face. The interviews were audio-taped and transcribed verbatim. The transcripts were analysed by following the principles of qualitative content analysis.

Results: Nine symptoms/forms of distress were identified. Those most frequently expressed were fatigue, changed bowel habits, and affected mental well-being, closely followed by nausea, loss of appetite and neurological problems. Of particular note were the affected mental well-being, the magnitude of the neurological problems described, the symptoms related to skin and mucous membrane problems, and the reports of distressing pain. Barriers to symptom control were only expressed by the patients in passing and very vaguely.

Conclusion: This study confirms other reports on most common symptoms in colorectal cancer. It also highlights the early onset of symptoms and provides data on less well-studied issues that warrant further study, namely affected mental wellbeing, the magnitude of the neurological problems and symptoms related to the skin and mucous membranes. Nurses need to be sensitive to the patients' need presented and not only noting symptoms/distresses they have guidelines for.
\end{abstract}

Keywords: Colorectal cancer, distress, qualitative content analysis, symptoms.

\section{INTRODUCTION}

Colorectal cancer (CRC) is the third most common cancer type worldwide [1]. CRC is often diagnosed when a patient presents with symptoms. Both the disease itself and the treatment have distressing symptoms and side-effects [2]. Early CRC produces no symptoms and many of the CRC symptoms are non-specific, such as changed bowel habits, general abdominal discomfort, weight loss with no apparent cause or constant tiredness - fatigue [3]. Characteristic symptoms of CRC are intermittent abdominal pain, nausea or vomiting, sometimes followed by secondary symptoms as bleeding or slime in the faeces. Increased intestinal sounds and stretched abdomen, changes of sense of taste, decreased appetite, dyspnoea, pain, fatigue and sleep disturbance have also been reported [4]. At a later stage, up to 40 per cent of CRC cases present an emergency condition with either bowel obstruction or perforation [2-5].

Surgery is the primary treatment for obtaining control of a tumour in the colon, but the role of surgery in advanced

*Address correspondence to this author at the Department of Medical and Health Sciences, Division of Nursing Science, Faculty of Health Sciences, Linköping University, SE-581 85 Linköping, Sweden; Tel: +46 101037768 ; Fax:+46 13 123285; E-mail: carina.bertero@liu.se colorectal cancer is limited. Surgery should be considered in the case of obstruction or resection of hepatic metastases [2, 4-6]. Post-surgical treatment of CRC depends on the stage of the cancer [3]. The addition of chemotherapy to the management of CRC has been an important contributing factor to the recent improved prognosis. All these treatment strategies should be tailored to the patient's individual needs $[1,3,5]$. Adjuvant therapy is a systematic treatment option administered with the intention of reducing the risk of relapse and death. The greatest benefit of adjuvant chemotherapy is seen in the most advanced but radically resected colorectal cancer $[2,4]$. Chemotherapy for advanced CRC leads to significant improvements in median survival, with survival approaching up to 2 years with this treatment compared with an estimated survival of 6 months with best supportive care [7]. Intravenous combination treatment with fluorouracil and oxaliplatin, such as FOLFOX has been adopted as the new standard for advanced colorectal cancer [4]. FOLFOX and the combination with oral capecitabin and i.v. oxaliplatin (XELOX) could be considered an effective treatment but might cause peripheral sensory neurotoxicity of the hand, feet, and mouth $[8,9]$. Treatment can exacerbate pre-existing symptoms, even though these symptoms vary depending on the type of cancer, and most patients already have disease-related symptoms before treatment [10]. These symptoms put together 
could be described as the 'symptom burden', which is defined as the subjective, quantifiable prevalence, frequency, and severity of symptoms placing physiological burden on patients, and producing multiple negative, physical, and emotional patient responses [11]. From a clinical perspective, it makes sense to focus efforts on symptoms/problems that affect the patient's daily life. To understand the patient's burden during chemotherapy treatment and plan effective symptom relief there is a need for more knowledge about the experience of symptoms from the patients' perspective. This study was designed to qualitatively identify and describe the most common symptoms among patients diagnosed with colorectal cancer, and find if there are barriers to reporting.

\section{SUBJECTS AND METHOD}

\section{Design}

A mixed method design using sequential mixed qualitative and quantitative research methods was used in order to capture the most common symptoms and forms of distress [12, 13]. The quantitative method consisted of patients filling in self-reported questionnaires about symptom and distress. Quantitative measures may only allow one aspect of a complex phenomenon such as symptoms and distress be explained, whereas a combination of quantitative and qualitative methods contribute to more comprehensive understanding of study outcomes [14]. Qualitative data was gathered through individual face-to face interviews with patients and next of kin and focus groups with health care professionals e.g. enrolled nurses, nurses and oncologists, to identify and describe symptom and distress from three different perspectives [15]. This article focuses on the results from the qualitative interview study with patients.

\section{Patients}

The patients were recruited as purposive sample [16] from two different hospitals in southern Sweden during Autumn 2008/2009. We had patients included from the quantitative survey study, which measured symptoms with instruments. All patients had knowledge about the phenomenon under study. Every third patient, (starting at patient no 3) was asked to participate in this interview study, but it was impossible to include all 36 patients in interviews, so we created a survey method for recruitment (see Table $\mathbf{1}$ and Fig. 1). The patients were informed and requested about participation in the project in oral and written form by the responsible physician together with the process leader (a nurse involved in the project at each clinic). Selection criteria were (a) being an adult, i.e. older than 18 years of age (b) being diagnosed with a colorectal cancer, (c) fulfilling a first cycle of chemotherapy (d) and being willing to share his/her lived experiences with us. At the time of data collection, the patients had experienced a similar volume intensity of chemotherapy (Fig. 1).

\section{Ethical Considerations}

Approval from the Committee on Research Ethics in Linköping was obtained. An enquiry about participation in the interview study was given to the patients by the nurses in conjunction with the responsible physician. In this way, both oral and written information about the study was given to the patients. The patients were informed about confidentiality, how they had been selected, and the aim of the study. Signed informed consent was required prior to participation. A total of 17 patients were approached and 13 agreed to participate.

Table 1. Patient Characteristics

\begin{tabular}{|l|c|}
\hline & $\mathbf{n}=\mathbf{1 3}$ \\
\hline \hline Gender & \\
\hline Female & 5 \\
\hline Male & 8 \\
\hline Chemotherapy & \\
\hline FOLFOX & 4 \\
\hline XELODA/XELOX & 9 \\
\hline Age & \\
\hline Median & 71 \\
\hline Range & $55-83$ \\
\hline Social status & \\
\hline Married/co-habitants & 8 \\
\hline Single/divorced & 4 \\
\hline Widow/widower & 1 \\
\hline
\end{tabular}

\section{Data Collection}

A general interview guide approach was used [18], and face-to face interviews were conducted by two experienced interviewers. This interview guide (see Fig. 2) was developed by the authors. Topics related to the interview guide were raised spontaneously by the interviewer or the interviewee, and probe questions were asked to give the patient opportunities to elaborate and give examples of more general statements. The interviews were conducted at a place convenient to the patients. Some interviews were conducted at the patients' homes, and some in a special room at the hospital. The interviews varied in length between 40 and 100 minutes, and were audio-taped and transcribed verbatim.

\section{Qualitative Analysis}

The analysis was a continuous process of reading the text while following the principles of qualitative content analysis, aiming to obtain valid inferences from texts [17]. The analyses were based on openness for variation in data, and a search for patterns, themes, regularities and contradictions by comparing statements from different interviews [18]. The transcripts were carefully and thoroughly read and re-read, line by line. The initial analytic step was coding. The codes were used to identify segments of the texts according to relevant themes, which could derive from the research question, e.g. symptoms, distress, barriers. Those themes evolved (added, deleted and merged) as the re-reading continued and analysis progressed $[15,17,18]$.

In order to increase the trustworthiness of the findings, 'investigator triangulation,' with analysis of the data by three researchers independently, was used [15], showing strong agreement. If needed, findings were discussed until consensus was reached. 


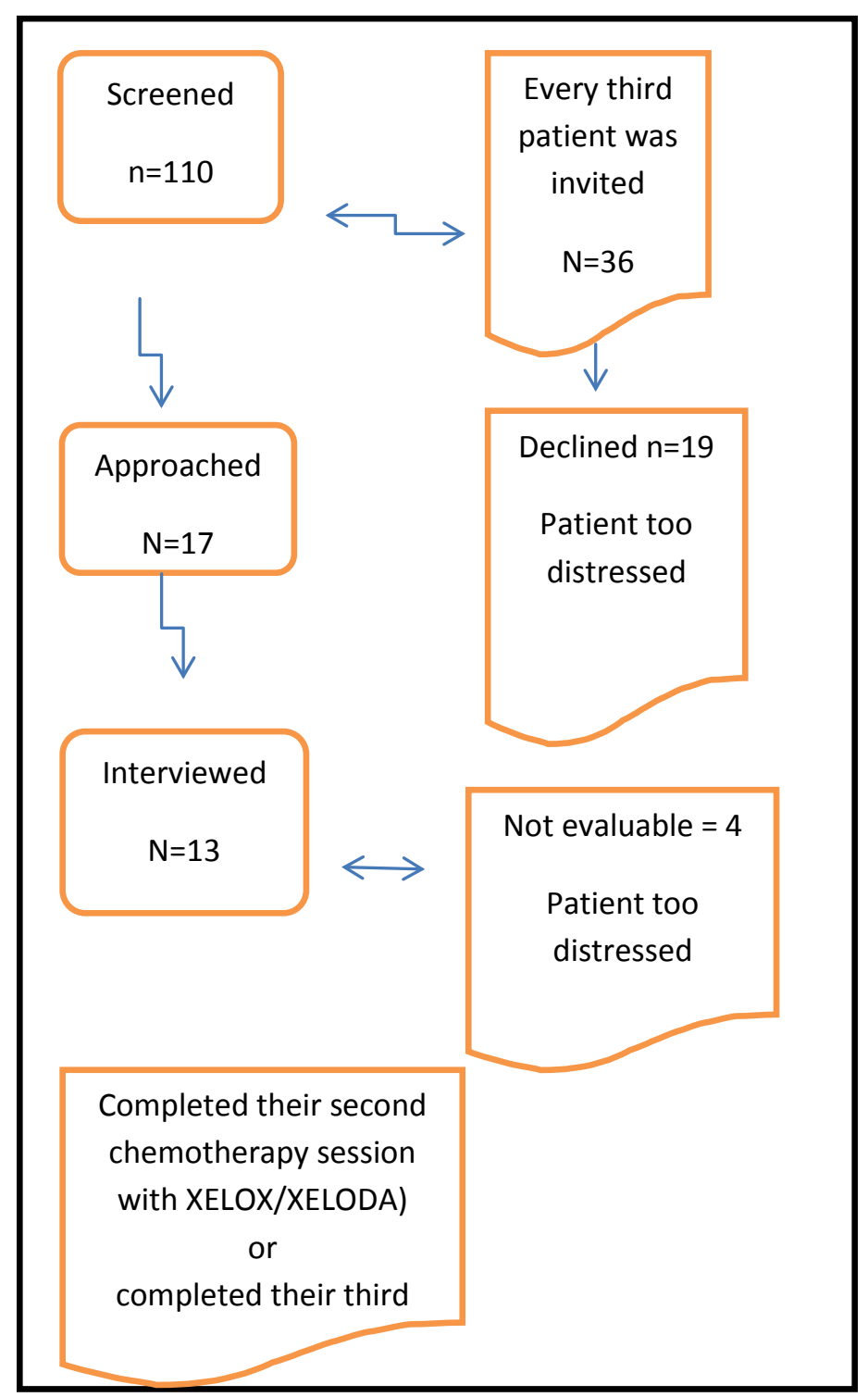

Fig. (1). Patient recruitment flowchart.

Interview guide
Presentation by the interviewer- some small talk
Repeated information about the study- informed consent
Audiotaping
Topics to be discussed during the interview
- What types of symptoms or forms of distress are you experiencing?
Follow-up questions to clarify the area under study

Fig. (2). Interview guide. 


\section{RESULTS}

A total of 13 patients agreed to participate and were interviewed (see Fig. 1). In the analysis of the verbatim transcripts, nine symptom or forms of distress were identified as being the most common among patients with colorectal cancer (see Table 2). Barriers for symptom control were only expressed by the patients by the way and very vaguely.

Table 2. A Summary of Symptoms Identified and Categorized According to Clear Descriptions

\begin{tabular}{|c|}
\hline $\begin{array}{l}\text { The Symptoms/Forms of Distress Most Frequently Expressed, in } \\
\text { Frequency Order }\end{array}$ \\
\hline $\begin{array}{l}\text { - Fatigue } \\
\text { - Changed bowel habits } \\
\text { - Affected mental well-being } \\
\text { - Nausea and Loss of appetite } \\
\text { - Neurological problems } \\
\text { - Distressing pain } \\
\text { - Altered body } \\
\text { - Skin and mucous membrane problems } \\
\text { - Affected sexual life }\end{array}$ \\
\hline Barriers to Reporting \\
\hline $\begin{array}{l}\text { - } \text { Stress level of the staff } \\
\text { - } \quad \text { Lack of time } \\
\text { - } \quad \text { Emotional concerns are hard to talk about }\end{array}$ \\
\hline
\end{tabular}

\section{Fatigue}

Fatigue was experienced by a majority of the patients. In some of the patients, the experiences of fatigue were present before their diagnosis and chemotherapy treatment. In connection with chemotherapy treatment, fatigue could be experienced the day they received the first treatment or could start during the second treatment period. Some described the duration of fatigue as lasting three to four days after the chemotherapy treatment, while others felt fatigued all the time. The symptom of fatigue was described as a single symptom or as occurring in combination with other symptoms. The intensity of fatigue varied from feelings of tiredness to exhaustion, and had effect on physical activities, social life and mood. For some patients, when they felt fatigued they could not do anything - sit, stand or lie down, or carry out basic activities of daily life such as showering or making the bed. As one patient expressed it; $I$ do not manage to do anything, just sleep. This was distressing and had consequences on their social life and mood. Some patients reported sleeping problems, saying that they could not sleep at all, had difficulty falling asleep, or woke up several times during the night. They tried to rest during the day, but felt like they could not sleep, and experienced rest more as a sort of nap; then at night, they could not sleep. I do not sleep, just laying there, resting.

\section{Changed Bowel Habits}

A majority of the patients reported changed bowel habits, mostly diarrhoea of different levels of severity and frequency, but also constipation. As expressed by several of the patients; ...alternating diarrhoea and constipation, ... The changed bowel habits were more often connected to the cancer treatment than the cancer itself. The stools were described as loose, bubbling or very fluid, sometimes with a different or bad smell. Also, flatulence or gas was mentioned as well as blood in the stools.

\section{Affected Mental Well-Being}

Affected mental well-being was also one of the more frequently mentioned forms of distress. The patients' well-being was affected by the symptoms and forms of distress they experienced, such as feeling irritated by the stomach trouble and in some cases having trouble with the stoma. Some of the patients were disappointed about the stoma and some had difficulty accepting it. There were also feelings that it was hard to handle the stoma, and that it gave a feeling of insecurity. The loss of body weight worried some patients and had consequences for two of the participants' medical treatment; leading to a lower prescription of chemotherapy, which affected their mental well-being. Mentally, the patients become more sensitive and more emotionally labile; not as stable as before. As one patient expressed it; I have become hypersensitive, and very easily moved. Several of the patients mentioned their feelings of apathy and listlessness. There was no energy to take the initiative, and it was hard to concentrate. There were feelings of worry and anxiety. There was uncertainty and worry regarding the next treatment and there was concern about the outcome of the disease and its treatment; "all the thoughts that came at night." The patients had many thoughts about life; they thought retrospectively and tried to distract themselves. These feelings of worry affected them and they became more vulnerable, and some of them became nervous and scared.

\section{Nausea and Loss of Appetite}

Nausea was frequently mentioned by the patients. For those who experienced nausea, taste changed, and loss of appetite or loss of weight were also often described. The patients mentioned they could not or did not want to cook or felt nausea when, for example, they opened the refrigerator. Someone described a feeling of hunger but still no real desire to eat. Food intake was described as less than normal, and could be half or even a third of what they usually ate. Nausea varied in intensity and duration but some patients described it as so severe that it turned out to be the worst symptom experienced. Vomiting was rarely reported. I am having a vomiting reflex (constantly), but I am not able to vomit.

The low food intake could also be related to mouth problems, linked to mucous membrane problems.

\section{Neurological Problems}

More than half of the patients reported different and distressing neurological problems. A pricking sensation in the fingers but also in the face, mouth, lips and throat was described. These pricking sensations were mostly related to coldness. Cold weather or being in contact with something cold gave these pricking sensations. When there was real coldness, the fingers and hands seemed to go numb. This pricking sensation could last from some minutes to several days, or up to one week. There were statements that this pricking sensation had become worse. The problems with the mouth and throat could sometimes be experienced as painful; ingesting something cold in the mouth was painful but also something warm. Brushing the teeth was painful.

Another distressing problem was a creeping sensation in the body. It could be described as restlessness; it was hard to be 
still, it was like a kind of internal worry. As one patient expressed it: This feeling...it is creeping in the whole body...there is an invasion of an army of ants.

\section{Distressing Pain}

Almost half of the patients said that they experienced different types of pain; even dreadful pain. This could be pain in the stomach; a kind of aching sensation, sometimes in combination with hiccups. The pain could be related to a feeling of soreness in the stomach but also cramps. As one patient expressed it; “.... I get kind of cramp...in the morning...but it disappear when I get something to eat...". These problems were anticipated as related to treatment. Some patients also commented on pain in the shoulders and feet due to infections caused by the treatment depressing their immune defence.

Distressing pain was something experienced at the time of diagnosis but it was also experienced during the treatment. Distressing pain sometimes affected sleep and sleep quality.

\section{Altered Body}

Some reflections from the participants were that there were bodily changes. The patient could alter in appearance by growing thin. Weight loss was reported as ranging between 6 to 25 kilograms, and people around had commented on it. Two patients mentioned that this with weight loss even affected treatment. The hair could become straggly, thinner or even be lost and others could experience increased growth of hair on the arms and beard. There were comments that the surgery resulted in an altered body; the belly looked curious, and there were ugly surgical scars. Those who had a stoma found that it changed the body and was something you did not want to put on show. As commented by one patient; you change how you dress, just to cover your altered body.

\section{Skin and Mucous Membrane Problems}

Approximately a third of the patients said that their skin and mucous membranes were affected. The skin was dry and itchy, or red and irritated. This redness occurred on the face, but also on the chest and on the feet. The skin was so dry that it became chapped; there were chaps on the fingers, the hands, and the heels. The skin on the fingers became wrinkled and sometimes the patients said it appeared as if they had shed the skin on their hands.

Regarding the mucous membrane, this problem was experienced as dry eyes but also dryness in the mouth. There were also blisters and a granular feeling in the mouth, on the tongue and on the lips. These problems affected the patients' food intake in several ways. Mouth problems caused difficulties with eating and swallowing solid food. It was easier when the consistency of food and drinks was modified and when they were served at lukewarm temperature, or when a straw was used for the intake of drinks. As one patient expressed it: "You had to stick to lukewarm food, then I drank a lot with a straw so the blisters wouldn't hurt so much, because it was so painful."

Another skin/mucous membrane problem mentioned was itching of the rump.

\section{Affected Sexual Life}

Few patients mentioned changes in their sexual life and the issues were almost often mentioned in connection with the information they had been given regarding the chemotherapy. The issues raised were that their libido was reduced, and concerns about whether this would be for a limited period or permanent were expressed. Someone said that the sexual life was not their priority right now. One patient had a reflection about this issue; ...sexual activity has completely finished, due to age or disease?

\section{Barriers to Report}

Most patients stated that there were no barriers to report symptoms or distresses. They then continued to say; “ ...the time is limited and there are many important issues to talk about." Barriers were not interpreted by the patients as hindrance or obstacles to report symptoms. The patients talked about different circumstances affecting the situation. Someone raised comments about the stress level of the staff, which made it difficult to take their time in a conversation about emotional concerns. Another patient mentioned it was more difficult to discuss sexual matters than other symptoms or concerns. Uncertainty about what were normal symptoms related to treatment or disease, and as a consequence, if they were supposed to discuss it with the staff, was also raised. One patient reported not taking the antiemetic drugs as described since the nausea was less severe than expected.

\section{DISCUSSION}

Research approaches such as the one used in the present study, i.e. qualitative face-to-face interviews, encourage the voicing of patients' experiences and emphasise understanding of the phenomenon, the symptoms and forms of distress, and thus give an understanding of the real world of these patients, expressed in their own words [16,17].

According to the patients in this study the most common symptoms and forms of distress were well known symptoms such as fatigue, changed bowel habits, nausea and loss of appetite. Affected mental well-being is perhaps less well documented in patients with colorectal cancer but was also frequently mentioned as a distressing symptom. An interesting finding in our study was the magnitude of the neurological problems described, the symptoms related to skin and mucous membrane problems, and the fact that almost half of the patients reported distressful pain.

Fatigue is one of the most frequent reported symptoms in cancer patients overall and in patients with colorectal cancer $[2,4,19]$, especially as a side-effect of cancer treatment [20]. Taking into account the great impact that fatigue has on the daily life of the patients it is remarkable that in a recent review and guide for nurses on how to manage toxicities associated with colorectal cancer chemotherapy, fatigue was not mentioned at all [21].

The patients in our study mentioned changed bowel habits, mostly diarrhoea but also constipation, as a common symptom, both before diagnosis and during chemotherapy, which is in line with earlier studies $[2,4,5]$. Because of the dual genesis of the bowel problems - the operation performed and the chemotherapy given - it is important to 
make a good anamnesis in order to initiate the best treatment option.

Nausea was frequently mentioned by the patients in our study, which is disappointing since evidence-based antiemetic guidelines are available at the units where the patients were treated. The patients received moderately emetogenic chemotherapy and were in the first part of their treatment (cycle 2 or 3 , depending on the type of chemotherapy), so nausea should not have been a distressing factor for more than half of the patients [22]. Since it was mentioned, this raises questions about whether the guidelines are followed or if they need to be revised. But it could also be that the patients do not report them. However, the nature of the experience of nausea might have been influenced by psychological distress.

Affected well-being was mentioned as a form of distress by a majority of the thirteen patients and could include distress related to effects of the disease, such as having a stoma, worries about losing body weight, or disappointment at being sick. Worries related to the outcome of the disease, anxiety, uncertainty, loss of energy and concentration problems were also mentioned. Our results are similar to those of an explored literature review [23] in regard to key aspects of uncertainty experienced by patients who have been diagnosed with breast, prostate, or colorectal cancer. Based on 40 articles, they identified three different sources that may cause or reinforce feelings of uncertainty in cancer patients. They include information related to issues after cancer has been diagnosed, and decisions about treatment and the effect of cancer-related uncertainty over the disease trajectory, on the lives of patients and their families [23]. Another study [24] also shows greater uncertainty one month after treatment ended, and uncertainty accounted for almost 70 percent of variance of functional and physical impairment changes. There is uncertainty regarding health issues, which is in conformity with our findings. The uncertainty and anxiety expressed in our findings are similar to the findings presented as fear and anxiety reflecting existential thoughts [25]. However, there are few studies focusing on the uncertainty and fear of going to treatment. In a study [26] presenting the health care professionals view of common symptoms and distresses among colorectal cancer patients, they pointed out that patients often are scared of coming to hospital. The hospital environment is unknown and the treatment with all its side-effects make the patients worried.

More than half of the patients in our study described neurological problems, and this was surprising. These were expressed as a pricking sensation or numbness in the fingers, mouth, lips, throat, or face, mostly related to coldness. We believe that the patients were describing neuropathy caused by oxaliplatin [21]. In a recent study investigating data from 1587 patients enrolled in three studies the incidence of grade 1,2 and 3 neuropathy was 45,28 , and $13 \%$, respectively. However, this data was based on the patients' total treatment period, whereas the patients in our study were at the beginning of their chemotherapy [27]. In another study [28] patients treated with oxaliplatin and interviewed after completed treatment described acute neuropathic symptoms temporally related to the time of infusion. Acute peripheral neuropathy is typically triggered by exposure to cold, and occurs shortly after oxaliplatin infusion and resolves within 14 days following treatment $[28,29]$. As most of the mild neurological symptoms will abate between the treatment cycles, the timing of questioning the patients is very important. Further studies on this issue are needed as it seems that timing of neurological symptoms is not well documented or researched. Grade of neuropathy, its effect on the patients, how these distresses affect daily life are all areas for further investigation. The issue about chronic neurotoxicity; symptoms becomes permanent affecting life and bringing forth limitations. There is also the issue about prolongation of the symptoms [28].

Almost half of the patient reported distressing pain. In a recent study [30], the result showed that patients with numbness, tingling or electric-like sensations reported more intense current pain, or continuous pain. This pain affected general activity, sleep, and relationships with people, which is in agreement with our findings. A problematic issue with distressful pain is that the patients reported it, but we do not know if there were any barriers to reporting it or if they could manage it. There are three different barriers identified in empirical research regarding pain management [31]; patient-related barriers, physician-related barriers and institutional barriers. When the patients were asked about barriers they did not mention any, or just very vaguely. The patients talked about different circumstances affecting the situation, which perhaps could be seen as physician-related barriers and institutional barriers. They stated that they have had the information given and more sensitive questions such as sexual life was found in brochures they had been given at their visits to the clinic. The patients experienced that there were signals from the health care professionals that focus on physical symptoms were the most important ones. This is in agreement with another study [26] showing that health care professionals had protocols for focusing on common symptoms related to treatments. As stated in the study [26] the physical symptoms were noted and those signals were sent to patients. The health care professionals felt secure about how to handle these physical symptoms, since there were guidelines. Those signals sent to patients regarding the importance of physical symptoms and manageable symptoms were also mentioned in our study. However, as mentioned previously regarding guidelines for nausea, even though there are guidelines and manageable symptoms they are not always the solution.

A third of the patients in our study reported distress related to skin and mucous membrane problems. These sideeffects are well known in all treatment settings including fluoropyrimidines, and can be dose-limiting. They occur in 45 to 100 per cent of patients treated with these therapies [32]. The skin problem could be rashes, which are often pruritic, but also other skin reactions such as xeros and eczema. Studies have reported that early identification of these symptoms could prevent negatively affected quality of life by dose-limiting or mitigating skin treatment [31-33]. Sometimes fissures or wounds on the palms and soles occur [34], and they should be treated.

Almost a third of the patients expressed thoughts about changes in their body. These changes were related to weight loss, scars after surgery, straggly hair, and skin problems. The patients did not recognise themselves and sometimes they did not like what they were seeing. This is agreement with the findings of a study about disrupted lives and threats 
to identity [34], but our findings do not point out anything about these kinds of disruptions.

The analysis conducted with qualitative content analysis offered a systematic way to describe and interpret the symptoms and forms of distress expressed [17, 18], and was also strengthened by three researchers independently conducting the analysis [16, 17]. There can always be argument about the sample size, but sample sizes in qualitative studies are often small $(15+/-10)$ for practical reasons related to time, funding, and analysis of the amounts of data collected from in-depth interviews [16]. With a sample size of 13 patients the representation is quite good; 8 males and 5 females, with a median age of 71 years.

It is noticeable, our study was conducted early in the treatment cycles, but even so, there were a considerable number of problems. Problems with peripheral neuropathy were much higher than expected. The patients had slightly different chemotherapy treatments, but at the time of interview, they were experiencing the same level of chemotherapy intensity. Although the patients in this study were interviewed relatively early in their treatment period they had profound symptoms and forms of distress. This shows the importance of scheduling regular and systematic assessments of patients' potential symptoms and forms of distress rather than waiting for the patient's own report. The assessments should ideally be initiated at the start of the chemotherapy period. Individual supportive care strategies can then be applied when necessary, based on evidencebased treatment guidelines. Standardised questionnaires probably catch most of the patients' problems but open questions should be added to capture less common symptoms or forms of distress, or experiences not acknowledged by the health care professionals.

\section{CONCLUSIONS}

This study identified nine symptoms or forms of distress as being the most common among patients treated for colorectal cancer. Those most frequently expressed were fatigue, changed bowel habits, and affected mental wellbeing, closely followed by nausea, loss of appetite and neurological problems. Issues that warrant further study are the affected mental well-being, the magnitude of the neurological problems described, the symptoms related to skin and mucous membrane problems and the fact that almost half of the patients reported distressing pain. Frequency and severity of symptoms are placing physiological burden on patients and affect them negatively; both bodily and mentally. The patients need to manage this burden, to manage their daily life. Ideally prospective, longitudinal studies initiated at the start of treatment, following patients through their entire treatment period, would provide useful information on the frequency, duration, and impact on daily life of the most important symptoms or forms of distress for patients with colorectal cancer. Nurses need to be sensitive to the patients' need presented and not only noting symptoms/distresses they have guidelines for.

\section{ACKNOWLEDGEMENTS}

We thank the patients participating, sharing their experiences with us. We also thank other members of the research team planning the large project that this study is part of; Gunilla Pettersson, Monica Rösliden Cecilia Bladh, Susanne Borén, and Viktoria Magnusson. We are also grateful to the Medical Research Council of Southeast Sweden and the Division of Nursing Science at the Department of Medical and Health Sciences for financial support.

\section{CONFLICT OF INTEREST}

Declared none.

\section{REFERENCES}

[1] Jemal A, Bray F, Center MM, Ferlay J, Ward E, Forman D. Global cancer statistics. CA Cancer J Clin 2011; 61(2): 69-90.

[2] Onkologiskt centrum. Nationellt vårdprogram för kolorektal cancer. 2008; Available from: http:/www.ocsyd.se/VP-verksamhe $\mathrm{t} /$ Gastrointest $\% 20 \mathrm{ca} /$ Vardprogr Kolorektal-cancer081120.pdf

[Accessed: February $1^{\text {st }}, 2011$ ].

[3] Knowles G, Sherwood L, Dunlop MG, et al. Developing and piloting a nurse-led model of follow-up in the multidisciplinary management of colorectal cancer. Eur J Oncol Nurs 2007;11: 21223.

[4] Labianca R, Berett GD, Kildani B, et al. Colon cancer. Crit Rev Oncol Hematol 2010; 74: 106-33.

[5] Simpson J, Scholefield JH. Treatment of colorectal cancer: surgery, chemotherapy and radiotherapy. Surgery 2008; 26: 329-33.

[6] Bruce C, Köhne C-H, Audisio RA. Treatment of advanced colorectal cancer in elderly. Eur J Surg Oncol 2007; 33: S84-7.

[7] Gill S, Blackstock W, Goldberg RM. Colorectal cancer. Mayo Clin Proc 2007; 82: 114-29

[8] Comella P, Casaretti R, Sandomenico C, Avallone A, Franco L. Role of oxaliplatin in the treatment of colorectal cancer. Ther Clin Risk Manag 2009; 5: 229-38.

[9] Qvotrup C, Jensen BV, Fokstuen T, et al. A randomized study comparing short-time infusion of axaliplatin in combination with capecitabine $\mathrm{XELOX}_{30}$ and chronomodulated $\mathrm{XELOX}_{30}$ as first-line therapy in patients with advanced colorectal cancer. Ann Oncol 2010; 21: 87-91.

[10] Khalid U, Spiro A, Baldwin C, et al. Symptoms and weight loss in patients with gastrointestinal and lung cancer at presentation. Support Care Cancer 2007; 15: 39-46.

[11] Gapstur RL. Symptom burden: a concept analysis and implications for oncology nurses. Oncol Nurs Forum 2007; 34: 673-80.

[12] Creswell J. Research design: qualitative, quantitative and mixed methods approaches. $2^{\text {nd }}$ ed. Thousand oaks, CA: Sage Publications 2003.

[13] Creswell JW, Fetters MD, Ivankova NV. Designing a Mixed Methods Study in Primary Care. Ann Fam Med 2004, 2: 7-12.

[14] Teddlie C, Tashakkori A. Foundations of mixed methods research. Integrating quantitative and qualitative approaches in the social and behavioral sciences. London: Sage Publications Ltd 2009.

[15] Patton MQ. Qualitative research and evaluation methods. $3^{\text {rd }}$ ed London, UK: Sage Publications Ltd 2002.

[16] Kvale S. Interviews an introduction to qualitative research interviewing. London, UK: Sage Publications Ltd 1996.

[17] Krippendorff K. Content analysis. An introduction to its methodology. London, UK: Sage Publications Ltd 2004.

[18] Mayring P. Qualitative content analysis 2000. Available at: http: //www.qualitative-research.net/index.php/fqs/article/view/1089 [Accessed: January 18th, 2010].

[19] Molassiotis A, Brearley S, Saunders M, et al. Effectiveness of a home care nursing program in the symptom management of patients with colorectal and breast cancer receiving oral chemotherapy: a randomized, controlled trial. J Clin Oncol 2009; 27(36): 6191-8.

[20] Winningha MI, Nail LM, Burke MB, et al. Fatigue and the cancer experience; the state of knowledge. Oncol Nurs Forum 1994; 21(1): 23-36.

[21] Grenon NN, Chan J. Managing toxicities associated with colorectal cancer chemotherapy and targeted therapy: a new guide for nurses. Clin J Oncol Nurs 2009; 13(3): 285-96.

[22] Herrstedt J, Rapoport B, Warr D, et al. Acute emesis: moderately emetogenic chemotherapy. Support Care Cancer 2011; 19(Suppl 1): $815-23$. 
[23] Shaha M, Cox CL, Talman K, Kelly D. Uncertainty in breast, prostate, and colorectal cancer: implications for supportive care. $\mathrm{J}$ Nurs Scholarsh 2008; 40(1): 60-7.

[24] Garofolo JP, Choppala S, Hamann HA, Gjerde J. Uncertainty during the transition from cancer patient to survivor. Cancer Nurs 2009; 32(4): E8-14.

[25] Shaha M, Cox CL. The omnipresence of cancer. Eur J Oncol Nurs 2003; 7(3): 191-6.

[26] Börjeson S, Starkhammar H, Berterö C. Common symptoms experienced among patients with colorectal cancer, and barriers to reporting symptoms or distress: the staff perspective. AustralAsian J Cancer 2011; 10 (1): 11-20.

[27] Ramanatha RK, Rothenberg ML, de Gramont A, et al. Incidence and evolution of oxaliplatin-induced peripheral sensory neuropathy in diabetic patients with colorectal cancer: a pooled analysis of three phase III studies. Ann Oncol 2010; 21(4): 754-8.

[28] Bennett BK, Park SB, Lin CS, Friedlander ML, Kiernan MC, Goldstein D. Impact of oxaliplatin-induced neuropathy: a patient perspective. Support Care Cancer 2012 [Epub ahead of print].
[29] Wilkes G. Therapeutic options in the management of colon cancer: 2005 update. Clin J Oncol Nurs 2005; 9: 31-43.

[30] Tofthagen C, McMillan SC. Pain, neuropathic symptoms and physical and mental well-being in persons with cancer. Cancer Nurs 2010; 33(6): 436-44.

[31] Jacobsen R, Liubarskiené Z, Møldrup C, Christrup L, Sjøgren P, Samsanavičiené J. Barriers to cancer pain management: a review of empirical research. Medicina 2009; 45(6): 427-33.

[32] Lacouture ME. Insight into the pathiophysiology and management of dermatologic toxicities to EGFR-targeted therapies in colorectal cancer. Cancer Nurs 2007; 30: 4S: S17-26.

[33] Galimont-Collen AFS, Vos LE, Lavrijsen APM, Ouwekerk J, Gelderblom H. Classification and management of skin, hair, nail and mucosal side- effects of epidermal growth factor receptor (EGFR) inhibitors. Eur J Cancer 2007; 43: 845-51.

[34] Hubbard G, Kidd L, Kerany N. Disrupted lives and threats to identity: The experiences of people with colorectal cancer within the first year following diagnosis. Health 2010;14: 131-46.

(C) Börjeson et al.; Licensee Bentham Open.

This is an open access article licensed under the terms of the Creative Commons Attribution Non-Commercial License (http://creativecommons.org/licenses/by-nc/3.0/) which permits unrestricted, non-commercial use, distribution and reproduction in any medium, provided the work is properly cited. 